\title{
MOTOR PERFORMANCES IN TWINS
}

Sir:

Increasing interest in the study of human motorics and the possibilities of intentional motor control obviously call for a genetic approach.

As a contribution to the problem of the importance of genetic factors in human motor abilities, I should like to briefly report on the results of a study based on the analysis of 13 tests administered to 30 twin pairs, $17 \mathrm{MZ}$ and $13 \mathrm{DZ}$. The heritability indexes calculated according to the different methods are shown in the Table.
It will be noted that, although heredity appears to play a role in general, not all the motor abilities considered are influenced to the same extent.

The impact of genetic factors appears to be higher in activities with speed and explosive strength and some marginal manifestations of strength. There, however, the results are not unequivocal.

The influence of hereditary factors might thus perhaps be thought to decline with increasing maturation and ontogenesis.

\begin{tabular}{|c|c|c|c|c|c|}
\hline \multirow[b]{2}{*}{ Test } & \multirow[b]{2}{*}{ Variable } & \multicolumn{4}{|c|}{ Heritability Index } \\
\hline & & Holzinger & Falconer & Nichols & $\begin{array}{l}\text { Analysis } \\
\text { of variance } \\
\left(h^{2}\right)\end{array}$ \\
\hline Coordination Test & Time (s) & 0.403 & 0.504 & 0.804 & 0.477 \\
\hline$» \quad »$ Mistakes & Number & 0.279 & 0.448 & - & 0.642 \\
\hline Vertical Jump & $\mathrm{cm}$ & 0.825 & 0.955 & - & 0.862 \\
\hline Medicine Ball Throw & $\mathrm{cm}$ & 0.785 & 0.604 & 0.658 & 0.599 \\
\hline Shuttle Run & & 0.848 & 0.810 & 0.874 & 0.896 \\
\hline Bent Arm Hang & & 0.354 & 0.254 & 0.331 & 0.621 \\
\hline Bending Trunk Forwards & $\mathrm{cm}$ & 0.895 & 0.334 & 0.341 & 0.689 \\
\hline Push-ups & Number & 0.277 & 0.266 & 0.407 & 0.222 \\
\hline Sit-ups & Number & 0.690 & 0.662 & 0.778 & 0.445 \\
\hline Dynamometry: Arm Strength & $\mathrm{kp}$ & 0.680 & 0.602 & 0.702 & 0.745 \\
\hline Dynamometry: Grip Strength & $\mathrm{kp}$ & 0.632 & 0.350 & 0.390 & 0.455 \\
\hline Dynamometry: Trunk Strength & $\mathrm{kp}$ & 0.680 & 0.314 & 0.349 & 0.568 \\
\hline Ergometry: Elbow Flexion & Number & 0.652 & 0.480 & 0.551 & 0.832 \\
\hline
\end{tabular}

RudolF KovÁr

Section of Anthropometrics

Department of Physical Education and Sports

Charles University

Prague 1, Czechoslovakia 